\title{
Morphological and molecular identification of first recorded Cladoceran organisms in the desert of Abu Dhabi, UAE
}

\begin{abstract}
Extracted organisms from water-rinsed sediments, collected by core sampling in a drydam basin within the desert of Abu Dhabi emirate (UAE), are the first documentary record of four Cladoceran species in this region. The organisms are Daphnia carinata King, D. similoides Hudec, D. cf. sinensis $\mathrm{Gu}, \mathrm{Xu}, \mathrm{Li}$, Dumont \& Han and Alona dentifera. Identification is based on both morphological identification and DNA sequencing approach. The genetic analyses suggest the existence of hybrids between the Daphnia species, for which $90-91 \%$ of examined specimen sequences matched the databank genome, while about $85 \%$ of Alona species' genetic sequences match the archived genome. Although genetic examination of the organisms indicated the presence of $D$. sinensis, it was not possible to identify it morphologically within the hatched organisms. These findings open a new trend in ecological and paleoecological research within the desert of the entire Arabian Peninsula. They may also result in the introduction of a valuable research program that expands the existing biodiversity database by documenting first time records of biota and new species of the region.
\end{abstract}

Keywords: Abu Dhabi, sediments, cladocera, desert wetlands, reservoirs
Volume 3 Issue 4 - 2018

\author{
Waleed Hamza, Gaber Ramadan, Mashael \\ AlKaabi \\ Department of Biology, College of Science, United Arab \\ Emirates University, United Arab Emirates
}

\begin{abstract}
Correspondence: Waleed Hamza, Department of Biology, College of Science, United Arab Emirates University, P.O. Box 1555 I Al Ain, United Arab Emirates, Tel +97-| 505-6389-80,
\end{abstract} Emailw.hamza@uaeu.ac.ae

Received: June 15, 2018 | Published: July 03, 2018

\section{Introduction}

Resting eggs of freshwater parthenogenetic crustaceans are usually found in the sediments of water bodies in which they live. Their resting state may be due to water quality deterioration and/ or temporary adverse environmental conditions. ${ }^{1-4}$ Cladocera populations in freshwater bodies are always characterizing its living invertebrates' community. This is especially so when Daphnia species dominate to constitute the dominant organism in the basin. As parthenogenetic organisms, Daphnia species adopt both asexual and sexual reproductive strategies, following the species conservation and the natural selection laws. ${ }^{5,6}$ In this respect, different researchers have found that sexually produced resting eggs are easily transported away from the site where they were laid, by means of water currents, wind, migratory birds, and even by shifting of agriculture soil and other human used products..$^{7-9}$ The easy transport of eggs means that the presence of Daphnia species in wetlands and/or temporary surface water bodies of arid areas does not mean that these species are native to the region. The Arabian Peninsula is known for its subtropical to arid environment, and the lack of permanent surface freshwater bodies. The wetlands in the Arabian Gulf region, in general, and in the United Arab Emirates, in particular, are characterized by ephemeral salt ponds or reservoirs that form immediately after rain fall on low lying areas with hyper saline substrate. In Abu Dhabi emirate (UAE), the dams constructed by the government for the protection of villages located in valleys provide short term (few weeks) retention of water after heavy rain falls. The temporary ponds may become havens for migrating birds. The resting eggs of crustacean species are attached to the feathers of these birds and are released into the pond waters. This may be an important factor in the hatching, survival and reproduction of the crustacean species. An example of this was in 1983, when cysts of Artemia salina were released from migrating birds into a treated sewage water basin in the Abu Dhabi desert. The appearance of $A$. salina in the basin made possible the nesting for the first time of a flamingo population (Phoenicopterus ruber) in the Abu Dhabi desert. ${ }^{10}$ The study of temporary lakes with short-term ecosystems as well as identification of resting eggs of crustaceans has so far not attracted research interest in the Middle East. However, the presence of experts in both morphological identifications and molecular phylogeny at local research and academic institutes increase the possibility of new species discoveries as well as geographical documentation of existing species. The present study emerges from the question: what organisms can survive in sediments of rainwater ponds retained for 4-5 weeks behind a dam in the desert? It aims to discover and identify both morphologically and genetically any crustacean eggs retrieved from a sediment core collected from the evaporated pond behind Al Shuwaib dam, which is located in the southern parts of Abu Dhabi emirate, UAE. This paleoecological approach is a new trend in understanding desert temporal wetlands within desert ecosystems.

\section{Materials and methods}

\section{Study area}

Al Shuwaib dam $\left(24^{\circ} 46^{\prime} 18.8^{\prime \prime} \mathrm{N}\right.$ and $55^{\circ} 48^{\prime} 15.2$ " E), is located close to Al Ain city (Figure 1) within Abu Dhabi Emirates (UAE). It is one of the largest water retention projects carried out by the UAE government to capture flood waters or torrential rainwater and to enhance reclamation. It has a storage capacity of 31 million cubic meters with a length of 3,000 meters and a dam height of 11 meters. ${ }^{11}$

\section{Sampling and analyses}

A sediment core sample was collected during March 2018 from the dry basin on the upstream side of the dam. The vertical sampling interval of the collected sediments was about $24.0 \mathrm{~cm}$ inside the Plexiglas core tube, which had a diameter of $7 \mathrm{~cm}$ (Figure 2). The core sediments were poured into a $2 \mathrm{~L}$ beaker and covered with 
desalinated bottled commercial drinking water at room temperature $\left(20 \pm 1^{\circ} \mathrm{C}\right)$, under 12:12 hours Light/Dark conditions for about 2 weeks. At the beginning of the third week, a few drops of freshly harvested unicellular monoclonal culture of Chlorella vulgaris Beyerinck, 1890 was added to the surface water covering the sediments. A few days after the addition of Chlorella cells, microscopic living organisms were observed on the sediment-water interface and swimming within the upper clear waters. Using a plastic dropper with tipped end, the microscopic organisms were transferred into a clean $250 \mathrm{ml}$ glass beaker filled with desalinated bottled commercial drinking water with a few drops of Chlorella culture cells. The taxonomic ranking of the collected organisms was performed via two different techniques. The first method is based on morphological identification, using both

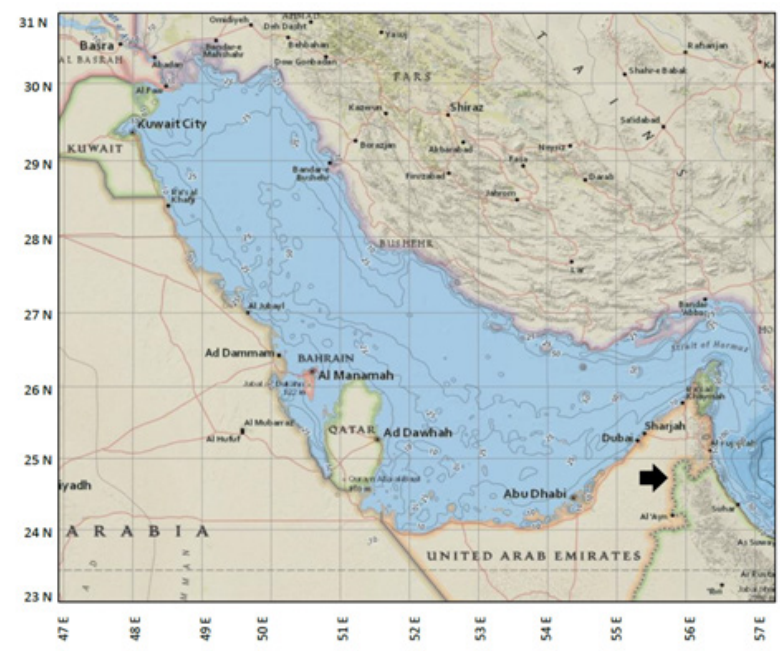

Figure I The Arabian Gulf and geographic position of Al Shuwaib Dam within the United Arab Emirates Territory. compound and stereo microscopes, and guided by a set of cladoceran taxonomic keys. ${ }^{11-16}$ The second technique involved a DNA sequencing process. Due to the unavailability of protocols and experience in our laboratory in the sequencing of freshwater crustaceans, the Macrogen LAB in South Korea provided the genetic phylogeny for the hatched organisms. Based on microscopic identification, speciesspecific individuals were isolated and preserved in $90 \%$ ethanol and transported in Eppendorf sealed cuvettes to the Macrogen LAB in South Korea. The Macrogen LAB processed the samples for DNA bar coding and sequences, following. ${ }^{17}$ The obtained results for each sample were matched and compared with their gene databank to confirm the genetic identification of the analyzed samples (Figure 3).

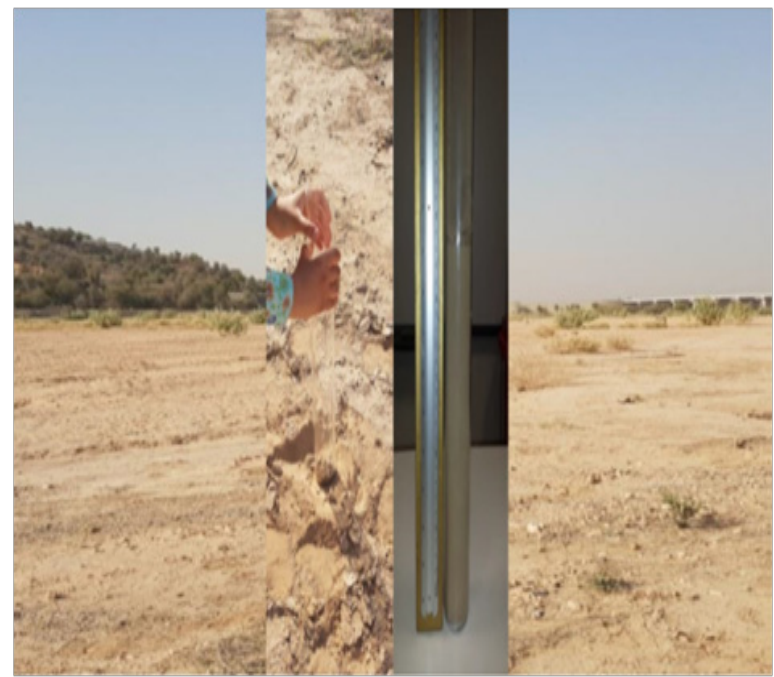

Figure 2 Sediments core sampling within Al Shuwaib Dam dry basin.

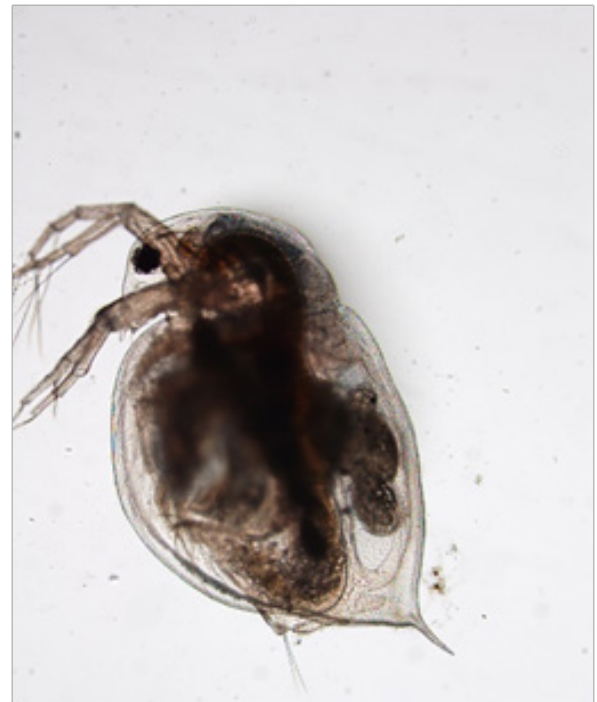

Daphnia carinata King, 1853

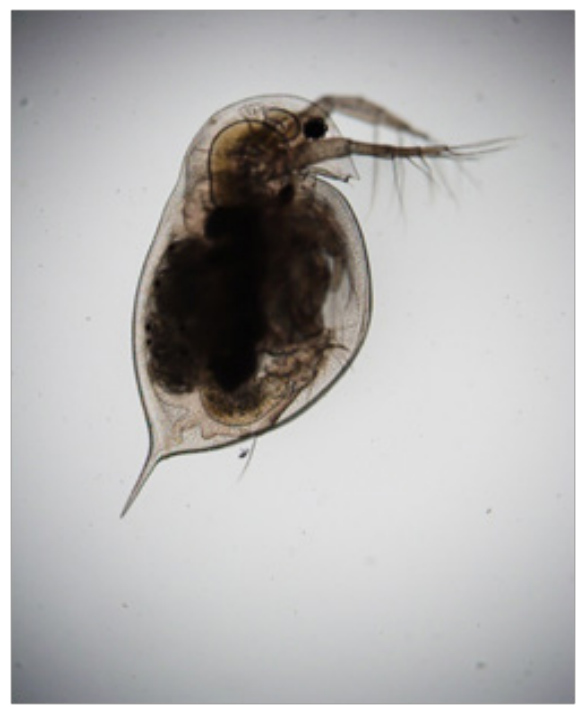

Daphnia similoides Hudec, 1991

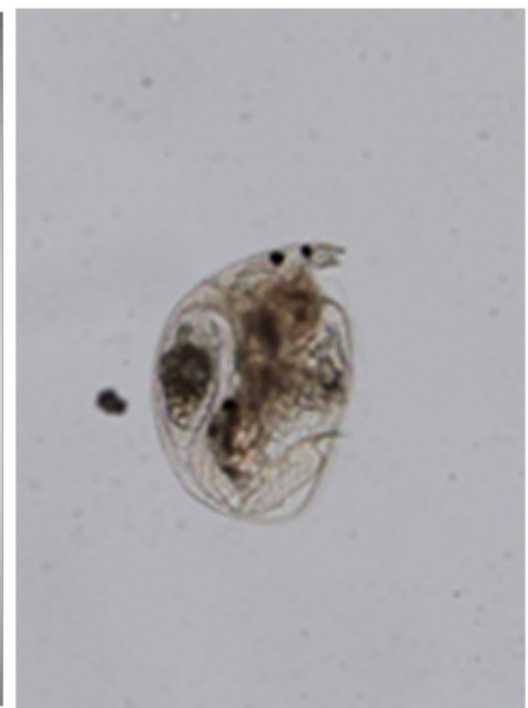

Alona dentifera (Sars, 190I)

Figure 3 Microscopic pictures of the identified three cladoceran species. 


\section{Results}

Based on microscopic morphological identifications and consulting the taxonomic references, the identified three species are found to belong to the hierarchal taxonomic structure shown in Table 1. Within the grown and reared cultures of the isolated Daphnia species, both asexual and sexual reproduction occurred and Daphnia male organisms were apparent (Figure 4). Thus, many Daphnia individuals were observed carrying resting eggs, or with its deteriorated body still with attachments of ephippian, and many ephippians were recorded at the bottom of the container where Daphnia was reared. This could be due to an increase in their densities or another factor, such as food quality. It was noticed that the first species to approach sexual reproduction within the identified populations belonged to D. similoides. While living $D$. carinata was rarely found to reproduce sexually in the laboratory. Another interesting observation is that although more than 3 months had passed since the collected sediments were covered with water in the laboratory, as yet unidentified new organisms hatched, though at a slower rate than before. Regarding the second method, the results of genetic analysis obtained from the Macrogen LAB confirmed the dominance of genetic features of the Daphnia species within the genetic sequencing of the analyzed specimens. The genetic matching within the databank complete or partial genome showed a percentage matching of $90-91 \%$ with $D$. carinata, $D$. similoides and

D. cf. sinensis, whereas for the Alona species, the genetic analyses showed a lower percentage (85\%) matching with the databank for the species $A$. dentifera (Table 2). Although the genetic identifications have indicated a $90 \%$ matching of the genetic features with $D$. c ff. sinensis, the morphological details were not sufficient to positively identify this species under the microscope (Figure 5).

Table I Classification structure of the morphologically identified species i.e. Daphnia carinata, Daphnia similoides and Alona dentifera

\begin{tabular}{llll}
\hline $\begin{array}{l}\text { Taxonomic } \\
\text { rank }\end{array}$ & $\begin{array}{l}\text { Daphnia } \\
\text { carinata }\end{array}$ & $\begin{array}{l}\text { Daphnia } \\
\text { similoides }\end{array}$ & $\begin{array}{l}\text { Alona } \\
\text { dentifera }\end{array}$ \\
\hline Kingdom & Animalia & Animalia & Animalia \\
Phylum & Arthropoda & Arthropoda & Arthropoda \\
Class & Branchiopoda & Branchiopoda & Branchiopoda \\
Order & Diplostraca & Diplostraca & Diplostraca \\
Family & Daphniidae & Daphniidae & Chydoridae \\
Genus & Daphnia & Daphnia & Alona \\
Species & carinata & similoides & dentifera \\
Authorship & King, I853 & Hudec, 1991 & Sars, 190I \\
\hline
\end{tabular}

Table 2 Summary of the genomic analyses report of Macrogen LAB, with matching percentage confirmation of the four identified species (Daphnia carinata Daphnia similoides, Daphnia c.f. sinensis and Alona dentifera)

\begin{tabular}{llllllllllllllll}
\hline \multicolumn{1}{l}{ Query } & \multicolumn{1}{c}{ Subject } & Score & \multicolumn{1}{c}{ Identities } \\
\hline No & Length & Start & End & Description & Length & Start & End & Bit & Raw & E-value & Match & Total & Pct. (\%) \\
\hline I & 699 & 3 & 681 & D.carinata & 1537 & 37 & 715 & 900 & 487 & 0 & 615 & 679 & 91 \\
2 & 699 & 11 & 662 & D. similoides & 658 & I & 652 & 872 & 472 & 0 & 592 & 652 & 91 \\
3 & 699 & 11 & 662 & D. sinensis & 658 & 1 & 652 & 861 & 466 & 0 & 590 & 652 & 90 \\
4 & 677 & 14 & 664 & A. dentifera & 652 & 1 & 652 & 654 & 354 & 0 & 554 & 653 & 85
\end{tabular}
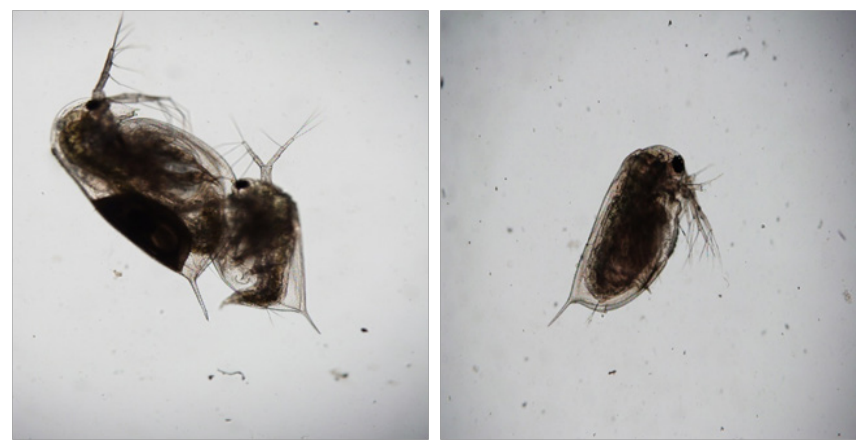

Figure 4 Pictures of sexual reproduction in Daphnia similoides (left) and male picture (right) from the reared laboratory organisms hatched from Shuwaib Dam sediments.
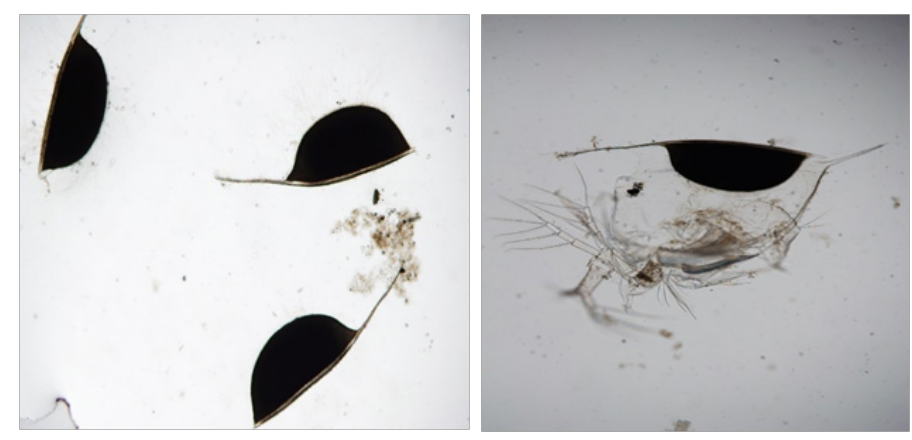

Figure 5 Photos of Ephippians (left) and its release from the dead Daphnia (right) from the reared laboratory organisms hatched from Shuwaib Dam sediments. 


\section{Discussion}

The Arabian Peninsula continues to be viewed by many scientists as a desert and arid environment where few tolerant organisms can survive its harsh conditions. This is partly true when high air temperatures and low-fertility sandy soils are considered. However, there have been dynamic developments during the last 50 years in the region, especially in commercial and trading exchange between the Arabian Gulf countries and the rest of the world. This is not only due to oil production and trade, but also to other activities including travel, tourism, job opportunities, as well as commercial and industrial activities. Transportation to and from the Gulf countries involves all types of carriers i.e. airplanes, ships, cars, trucks, tankers. However, the most important carriers in this study are wind and migrating birds. All types of soil particles and/or detrital materials with suitable weight are passively transported without specific destination. In fact, in the present study, the hatched cladoceran species from the collected dam sediments could have been transported into the study area, either by wind or by release from the feathers of migrating birds, which populate the dam area following rainy spells. As often mentioned in the literature, the arid and sandy soils of Abu Dhabi Emirate lie in an environment dominated by low-lying sandy deserts, extensive salts-flats in the coastal areas, gravelly plains covering wide areas in both the far west and east, and alluvial plains. ${ }^{18-20}$ These conditions do not allow for perennial freshwater bodies within the Emirates territory. Rare periods of heavy rainfalls produce transient ponds that evaporate after a few days or are transformed into saline pools. In our study we hypothesize that ephippians have been transported by wind or were attached to migrant bird feathers and were deposited in the areas nearby to the dam. These ephippians may or may not be able to hatch after arrival, depending on the first fresh rainwater accumulation behind the dam to make hatching possible. Hatched individuals initially reproduced asexually, but after few days, began to reproduce sexually as water salinity climbed and/or water volume decreased due to the high infiltration in the porous sandy soils and high evaporation rates.

In the present study, morphological identification by microscopes has been assisted by taxonomic keys and professional experience with cladoceran organisms. On the other hand, the genetic analyses depend on matching the DNA sequence of the examined organisms with the existing complete or partial genome in the gene databanks. This results in either confirmation of the morphological identification, or correction of biased morphological identification. Moreover, it may rename a species or discover a new species. The inability of morphological identification to find $D$. $c f$. sinensis amongst the hatched organisms can be explained if hybridization between different Daphnia species is considered. Its genomic features may be mixed with both identified species i.e. D. carinata and D. similoides. In their research, ${ }^{21}$ found that comparing parental and hybrid taxa offers the possibility to test evolutionary theories of selection, adaptation and gene flow. It has also been observed that the outcome of hybridization may be considered as a contest between fusion and speciation, depending on the fitness of hybrid and the initial level of assortative mating ${ }^{22}$ In the present study, the ability of Daphnia species to survive and reproduce within very short and limited time in such harsh desert environments requires a special fitness. This fitness may be achieved unless a hybridized clone emerges from other pure ones. This has led to speculate that hybridization should have occurred before the organism has reached a new habitat in order for it to be able to tolerate less than ideal environmental conditions.

The detection of $D$. cf. sinensis by genetic analysis does not mean that the morphological identification was unsuccessful in doing so. In their study for the revision of Old World $D$. similis group, Papova et $a .^{6}{ }^{6}$ discovered that the four taxa of the similis group (confused previously with Daphnia similis Claus, 1876) have distinct distributional ranges in the Old World, from extremely wide, spanning several biogeographic regions (such as $D$. sinensis), to regional endemics (e.g. D. similoides). They also added that the Daphnia similis group provides another example in the cladocerans insomuch as the study of males yields more valuable characteristics for taxonomy than the study of parthenogenetic females. These conclusive remarks have confirmed that, in previous studies, substantial confusion in the identification of the $D$. similis group (including $D$. similoides and $D$. sinensis) has occurred, perhaps due to the high percentage of morphological similarities amongst them. It is also possible that the newly identified species (D. sinensis), shares not only morphological features but also substantial part of its similar genetic sequence codes with $D$. similoides. This could explain why our study has succeeded in morphologically identifying only $D$. similoides. Genomic analysis becomes necessary in cases like these, where the expert human eye and powerful microscopes are incapable of recognizing genetically hybridized organisms. In addition, the occurrence of sexual reproduction in $D$. similoides more than $D$. carinata in the present study is a phenomenon that needs further investigation, especially as Papova et al. ${ }^{6}$ has indicated the importance of male taxonomy over that of parthenogenetic females in the $D$. similis group. Although the genetic analysis reveals the presence of $D$. cf. sinensis within the reared organisms hatched from sediments, there is no microscopic picture available for its morphometric features to document here. Therefore, it may be concluded from the present study that $D$. sinensis can only be announced genetically but not documented physically. That is why, only pictures and classifications of the other three morphologically identified species are listed in Table 1. The presence of Alona dentifera species, with only $85 \%$ matching against the databank genome, may also reflect its hybridization with another species. The ability of this species, together with Daphnia to remain in sediments with temperatures that may reach $>50 \mathrm{C}^{\mathrm{o}}$ for at least 3 months each year, then to hatch and grow to reproduce for a very short period of time is an example of perfect fitness of those identified species. Finally, we conclude that the present study has not only documented the first record of cladoceran species in the Emirate of Abu Dhabi, but has also confirmed that organismal fitness through genetic interspecific hybridization is the way to conserve its species through challenging environmental conditions. This study can lead to future paleoecological research with more accuracy that may highlight the history of cladoceran organisms in the region.

\section{Acknowledgments}

The authors express their grateful to Dr. Ranjit Viajan for his help in connecting with the Macrogen Lab. South Korean. Our gratitude is extended to Prof. T. Fowler for his revision of the manuscript editing.

\section{Conflict of interest}

The author declares there is no conflict of interest. 


\section{References}

1. Alekseev V, Lampert W. Maternal control of resting-egg production in Daphnia. Nature. 2001;414(6866):899-901.

2. Crispim MC, Watanabe T. What can dry reservoir sediments in a semi-arid region in Brazil tell us about cladocers. Hydrobiologia. 2001;442(1-3):101-105.

3. Vandekerkhove J, Declerck S, Brendunonck L, et al. Hatching of cladoceran resting eggs: temperature and photoperiod. Freshwater Biology. 2005;50(1):96-104.

4. Santangelo JM, Araujo LR, Esteves FA, et al. Method for hatching resting eggs from tropical zooplankton: effects of drying or exposing to low temperatures before incubation. Acta Limnologica Brasiliensia. 2011;23(1):42-47.

5. Lampert W. Daphnia: development of a model organism in ecology and evolution. Excellence in Ecology. 2011;4(1):85-87.

6. Papova EV, Petrusek A, Korinek V, et al. Revision of the Old World Daphnia (Ctenodaphnia) similis group (Cladocera: Daphniidae). Zootaxa. 2016;4161(1):1-40.

7. Kattel GR, Battarbee RW, Mackay A, et al. Are cladoceran fossils in lake sediment samples a biased reflection of the communities from which they are derived?. Journal of Paleolimnology. 2007;38(2):157-181.

8. Duggan IC, Robinson CV, Burns CW, et al. Identifying invertebrate invasion using morphological and molecular analyses: North American Daphnia Pulex in New Zealand freshwaters. Aquatic Invasions. 2012;7(4):585-590.

9. Nevalainen L, Luoto TP. Sedimentary Chydorid (Cledocera) Ephippia in relation to lake ecological quality in Austrian Alps. J Limnology. 2013;72(1):52-61.

10. Hamza, W, Al Dhaheri S, E1-Sayed A. Pioneer limnological observations on the developed ecosystem of a permanent lake in Abu Dhabi Desert, UAE. Verh. Internat. Verein. Limnol. 2006;29(3):1559-1564.
11. UAE Government. Water security strategy 2036. The official portal of the UAE government. UAE; 2018.

12. Sars GO. Daphnia carinata King and its remarkable varieties. Arch Math Nat B. 1914;34:1-14.

13. Arora GL. Fauna of Lahore. Entomostraca (water fleas) of Lahore. Punjab University. Zoology Department Bull. 1931;1:62-100.

14. Abonyi A. Über die Artberechtigung der Hyalodaphnia hypsicephala Daday. Int Revue ges Hydrobiol. 1916;7(6):456.

15. Hebert PDN. Clonal diversity in cladoceran populations. Population Biology: Retrospect and Prospect. In: King CE, Dawson PS, editors. Columbia University Press. New York; 1983. 235 p.

16. Smirnov NN, Timms BV. A revision of the Australian Cladocera (Crustacea). Rec Aust Mus Suppl. 1983;1:1-132.

17. Benzie JAH. The Systematics and population structure of the Daphnia carinata complex in Australia. Ph.D Thesis. Australian National University. Canberra; 1985.

18. Zhang Z, Schwartz S, Wagner L, et al. A greedy algorithm for aligning DNA sequences. J Comput Biol. 2000;7(1-2):203-14.

19. Abdelfattah MA, Shabbir SA. A Comparative Characterization and Classification of Soils in Abu Dhabi Coastal Area in Relation to Arid and Semi-Arid Conditions using USDA and FAO Soil Classification Systems. Arid Land Research and Management. 2004;21(3):245-271.

20. Suginome M, Baba K. Studies of mass culture of Daphnid. No.1. Growth, maturation and reproduction of Daphnia carinata King cultured under varied conditions of temperature and food- and population-density. Bull Freshwat Fish Lab, Tokyo. 1963;13:13-30.

21. Vandekerkhove J, Declerck S, Brendunonck L, et al. Hatching of cladoceran resting eggs: temperature and photoperiod. Freshwater Biology. 2005;50(1);96-104.

22. Venkataraman K, Job SV. Effect of temperature on the development, growth and egg production in Daphnia carinata King (Cladocera: Daphnidae). Hydrobiologia. 1980;68(3):217-224. 